\title{
Perpindahan Panas pada Media Berpori Menggunakan Metode Elemen Hingga
}

\author{
Surya Ningsih ${ }^{* 1}$, Wahyu Srigutomo ${ }^{2}$ \\ ${ }^{1,2}$ KK Fisika Bumi dan Sistem Kompleks Program Studi Magister Fisika \\ FMIPA Institut Teknologi Bandung \\ e-mail: suryaningsih885@yahoo.co.id,wahyu@fi.itb.ac.id
}

\begin{abstract}
Abstrak
Masuknya aliran panas dari bawah reservoir ke dalam medium berpori di dalamnya mempengaruhi kondisi tekanan, entalpi, dan temperatur di dalam reservoir. Hal ini terjadi karena panas mengalir dari daerah bertemperatur tinggi ke daerah bertemperatur lebih rendah. Panas mengalir melalui daerah patahan (fracture zone) yang memiliki permeabilitas dan porositas lebih tinggi dari daerah sekitarnya di dalam reservoir untuk kemudian terjadi perpindahan panas secara konduksi menuju daerah sekitarnya. Tulisan ini mensimulasikan proses perpindahan panas dengan mengamati distribusi temperatur dan aliran fluida pada medium berpori. Metode numerik yang digunakan adalah metode elemen hingga. Hasil yang ditampilkan adalah distribusi tekanan, kecepatan aliran fluida, dan distribusi temperatur dan kemudian diinterpretasikan.
\end{abstract}

Kata kunci: permeabilitas, porositas, kecepatan, distribusi temperatur, metode elemen hingga.

\section{PENDAHULUAN}

Perpindahan panas pada sistem panas bumi adalah perpindahan energi panas dari daerah yang bertemperatur tinggi ke daerah yang bertemperatur lebih rendah. Perpindahan panas dapat terjadi dalam tiga mekanisme, yaitu: konduksi, konveksi, dan radiasi. Pada sistem panas bumi, hanya konduksi dan konveksi yang berperan. Perpindahan panas secara konduksi adalah perpindahan energi karena adanya getaran molekul pada batuan. Perpindahan panas secara konveksi adalah perpindahan energi melalui pergerakan dari fluida.

Perpindahan panas yang terjadi di dalam bumi merupakan persoalan kompleks karena melibatkan banyak parameter dan bersifat inhomogen dan anisotropi. Sehingga penyelesaian persoalan perpindahan panas dalam bumi memerlukan asumsi -asumsi untuk menyederhanakan permasalahan. Untuk masalah yang kompleks dapat dikerjakan dengan menggunakan metode numerik. Salah satu metode numerik yang dapat digunakan adalah Metode Elemen Hingga (Finite Elemen Method). Metode elemen hingga adalah salah satu metode numerik yang dapat digunakan untuk memecahkan persoalan syarat batas dalam bentuk persamaan differensial dengan mencari solusi pada domain-domain kecil dengan menerapkan syarat batas.

Ide utama dalam metode elemen hingga adalah membagi geomerti domain dari permasalahan menjadi sub-sub domain yang lebih kecil atau sering disebut sebagai elemen hingga. Bentuk elemen yang sering digunakan adalah elemen segitiga dan quadrilateral. Pada tulisan ini Penulis melakukan perhitungan solusi permasalahan syarat 
batas dengan menggunakan metode elemen hingga pendekatan Galerkin. Metode elemen hingga diterapkan pada persamaan perpindahan panas konduksi-konveksi dengan solusi berupa distribusi temperatur pada domain dua dimensi.

\section{METODE PENELITIAN}

\subsection{Metode Elemen Hingga}

Dalam penelitian ini digunakan elemen hingga (Finite Elemen) untuk memecahkan persamaan persamaan perpindahan panas dan kecepatan aliran fluida. Metode ini digunakan untuk menyelesaikan persamaan parsial dengan membagi setiap sistem menjadi elemen-elemen dengan geometri tertentu. Dari elemen-elemen tersebut akan tersusun matriks persamaan linear. Dalam proses penyelesaian elemen hingga diperlukan elemen dengan geometri tertentu beserta fungsi bentuk atau shape function, yang mempresentasikan ciri solusi dari setiap elemen. Dalam penelitian ini digunakan elemen segitiga (2-D) dengan fungsi bentuk linear.

\subsubsection{Elemen Segitiga Linear}

Zienkiewick dkk (2005) menjelaskan bahwa pada elemen segitiga, interpolasi linear untuk aproksimasi fungsi tertentu dapat dinyatakan sebagai berikut:

$$
u(x, y)=\alpha_{1}+\alpha_{2} x+\alpha_{3} y
$$

Pada gambar 1, nilai $T$ pada masing-masing titik adalah:

$$
\begin{aligned}
& T_{i}=\alpha_{1}+\alpha_{2} x_{i}+\alpha_{3} y_{i} \\
& T_{j}=\alpha_{1}+\alpha_{2} x_{j}+\alpha_{3} y_{j} \\
& T_{k}=\alpha_{1}+\alpha_{2} x_{k}+\alpha_{3} y_{k}
\end{aligned}
$$

Yang menghasilkan koefisien-koefisien

$$
\begin{aligned}
& \alpha_{1}=\frac{1}{2 A}\left[\left(x_{j} y_{k}-x_{k} y_{j}\right) u_{i}+\left(x_{k} y_{i}-x_{i} y_{k}\right) u_{j}+\left(x_{i} y_{j}-x_{j} y_{i}\right) u_{k}\right] \\
& \alpha_{2}=\frac{1}{2 A}\left[\left(y_{j}-y_{k}\right) u_{i}+\left(y_{k}-y_{i}\right) u_{j}+\left(y_{i}-y_{j}\right) u_{k}\right] \\
& \alpha_{3}=\frac{1}{2 A}\left[\left(x_{k}-x_{j}\right) u_{i}+\left(x_{i}-x_{k}\right) u_{j}+\left(x_{j}-x_{i}\right) u_{k}\right]
\end{aligned}
$$

dengan $A$ adalah luas elemen segitiga.

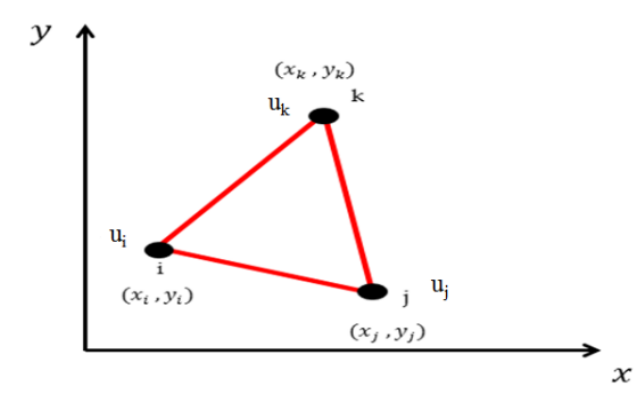

Gambar 1 Elemen Segitiga 
Dengan mensubstitusikan $\alpha_{1}, \alpha_{2}$, dan $\alpha_{3}$ akan diperoleh fungsi bentuk untuk elemen segitiga.

$T=N_{i} T_{i}+N_{j} T_{j}+N_{k} T_{k}=\left[\begin{array}{lll}N_{i} & N_{j} & N_{k}\end{array}\left[\begin{array}{l}T_{i} \\ T_{j} \\ T_{k}\end{array}\right]\right.$

dengan

$N_{i}=\frac{1}{2 A}\left(a_{i}+b_{i} x+c_{i} y\right)$

$N_{j}=\frac{1}{2 A}\left(a_{j}+b_{j} x+c_{j} y\right)$

$N_{k}=\frac{1}{2 A}\left(a_{k}+b_{k} x+c_{k} y\right)$

dan

$a_{i}=x_{j} y_{k}-x_{k} y_{j} \quad b_{i}=y_{j}-y_{k} c_{i}=x_{k}-x_{j}$

$a_{j}=x_{k} y_{i}-x_{i} y_{k} \quad b_{j}=y_{k}-y_{i} c_{j}=x_{i}-x_{k}$

$a_{k}=x_{i} y_{j}-x_{j} y_{i} \quad b_{k}=y_{i}-y_{j} c_{k}=x_{j}-x_{i}$

\subsubsection{Teorema residual dan formulasi Galerkin}

Metode residual adalah metode aproksimasi untuk menyelesaikan persamaan differensial dengan memberikan nilai bobot pada residual atau sisa dari persamaan aproksimasi dalam Zienkiewicz dkk (2005). Formulasi Galerkin digunakan agar residual menjadi minimal dengan mengalikan integrasi residual dengan suatu fungsi bobot $w_{i}(x)$;

$$
\int_{\Omega} w_{i}(x) R(x) d x=0
$$

Dimana fungsi bobot diganti dengan fungsi bantu atau shape function dari metode elemen hingga yang digunakan sebagai aproksimasi. Dengan meninjau persamaan kecepatan aliran fluida dan persamaan perpindahan panas konduksi-konveksi pada keadaan tunak serta menerapkan metode residual dan syarat batas Neumann maka diperoleh:

$$
\begin{aligned}
& K_{i j}^{e}=\iint_{\Omega} N_{i} \rho C_{p}\left[u_{x} \frac{\partial N_{j}}{\partial x}+u_{y} \frac{\partial N_{j}}{\partial y}\right] d x d y \\
& +\left\{-\iint_{\Omega^{e}}\left[k_{x} \frac{\partial N_{i}}{\partial x}+k_{y} \frac{\partial N_{j}}{\partial y}\right] d x d y\right\} \\
& f_{i}^{e}=\iint_{\Omega^{e}} N_{i} Q d x d y \\
& p_{i}^{e}=\oint_{\Gamma^{e}} N_{i}\left(k_{x} \frac{\partial T}{\partial x} n_{x}+k_{y} \frac{\partial T}{\partial y} n_{y}\right) d l
\end{aligned}
$$

\subsubsection{Langkah Pemodelan}


Untuk mengetahui distribusi temperatur terlebih dahulu mencari kecepatan aliran fluida dengan menggunakan persamaan (4), kemudian persamaan (4) diterapkan ke dalam metode elemen hingga. Solusi dari persamaan (4) kemudian di masukkan ke dalam persamaan (6) dan diterapkan kedalam metode elemen hingga.

Adapun model domain yang digunakan adalah sebagai berikut:

a. Model reservoir bidang datar

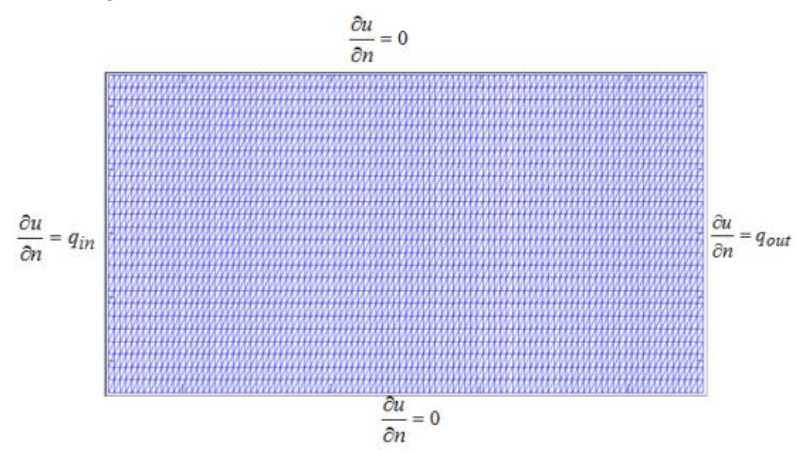

Gambar 2 Mesh dan syarat batas pemodelan non topografi

b. Model reservoir topografi lembah

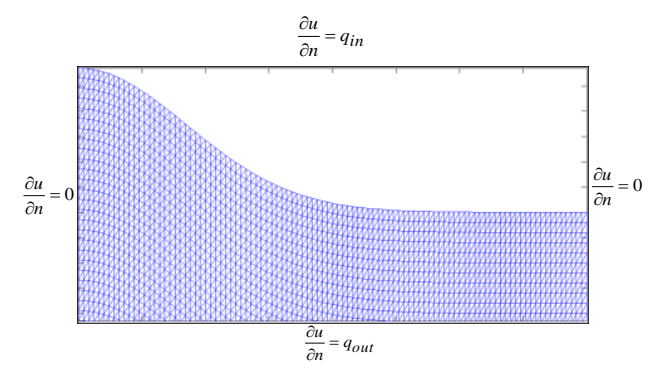

Gambar 3. Mesh dan syarat batas pemodelan topografi lembah

c. Model reservoir topografi gunung

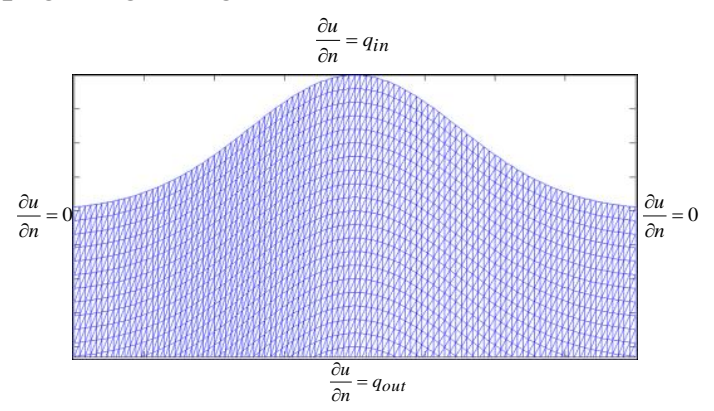

Gambar 4 Mesh dan syarat batas pemodelan topografi gunung

Parameter fisis yang digunakan adalah sebagai berikut:

Tabel 1 Paramter batuan dan fluida pada reservoir panas bumi

\begin{tabular}{|c|c|c|}
\hline $\begin{array}{c}\text { Parameter } \\
\text { fisis }\end{array}$ & Nilai & Satuan \\
\hline$\kappa_{1}$ & $1.5 \times 10^{-12}$ & $\mathrm{~m}^{2}$ \\
\hline
\end{tabular}




\begin{tabular}{|c|c|c|}
\hline$\kappa_{2}$ & $9.85 \times 10^{-12}$ & $\mathrm{~m}^{2}$ \\
\hline$\kappa_{3}$ & $1 \times 10^{-12}$ & $\mathrm{~m}^{2}$ \\
\hline$\mu$ & $0.1102 \times 10^{3}$ & $\mathrm{~Pa} . \mathrm{s}$ \\
\hline $\mathrm{k}_{1}$ & 2.34 & $\mathrm{~W} / \mathrm{m}^{\circ} \mathrm{C}$ \\
\hline $\mathrm{k}_{2}$ & 2.0 & $\mathrm{~W} / \mathrm{m} .{ }^{\circ} \mathrm{C}$ \\
\hline $\mathrm{k}_{3}$ & 0.2 & $\mathrm{~W} / \mathrm{m}^{\circ} \mathrm{C}$ \\
\hline$\rho_{w}$ & 998.2 & $\mathrm{Kg} / \mathrm{m}^{3}$ \\
\hline $\mathrm{C}_{\mathrm{pw}}$ & 4200 & $\mathrm{~J} / \mathrm{kgK}$ \\
\hline $\mathrm{C}_{\mathrm{ps}}$ & 2250 & $\mathrm{~J} / \mathrm{kgK}$ \\
\hline
\end{tabular}

\subsection{Tinjauan Pustaka}

\subsubsection{Sistem Panas Bumi}

Panas bumi merupakan energi panas yang terbentuk secara alami dan tersimpan dalam bentuk air panas atau uap panas pada kondisi geologi tertentu pada kedalaman beberapa kilometer di dalam kerak bumi. Sistem panas bumi terdiri dari 5 bagian, yaitu: Sumber panas, reservoir, fluida reservoir, lapisan penudung, dan siklus hidrologi.

\subsubsection{Sifat Fluida Satu Fasa}

Pada paper ini yang ditinjau adalah fluida satu fasa yaitu fasa air. Adapun sifat dari fluida tersebut yaitu, volume spesifiknya adalah perbandingan antara volume fluida dengan massanya, densitas fasa fluida merupakan perbandingan antara massa dengan volume fasa fluida, dan viskositas yang merupakan ukuran kelembaman suatu fluida untuk mengalir.

\subsubsection{Sifat Batuan}

Media berpori pada sistem panas bumi merupakan batuan yang memiliki pori sebagai tempat penyimpanan fluida panas. Reservoir pada sistem panas bumi merupakan batuan yang permeabel yang memiliki sifat porositas yang tinggi. Permeabilitas suatu batuan merupakan ukuran kemampuan batuan untuk mengalirkan fluida. Parameter yang menyatakan besarnya kemampuan suatu batuan untuk menghantarkan panas secara konduksi disebut konduktivitas panas. Secara matematis untuk satu dimensi dinyatakan sebagai berikut:

$$
K=\frac{Q}{(d T / d z)}
$$

dengan Q adalah laju aliran panas per satuan luas dan dT/dz adalah gradien temperatur. Satuan dari konduktivitas panas adalah W/m.K. Panas spesifik batuan adalah suatu parameter yang menyatakan banyaknya panas yang diperlukan untuk menaikkan suhu persatuan massa batuan tersebut sebesar $1{ }^{\circ} \mathrm{C}$.

\subsubsection{Aliran Fluida dalam Media Berpori}

Fluida akan mengalir dalam media berpori apabila media tersebut empunyai permeabilitas yang searh dengan tenaga pendorong. Persamaan yang menggambarkan mengenai aliran fluida dalama media berpori pertama kali dikembangkan oleh Henry Darcy (1856). Persamaan tersebut merupakan persamaan yang menunjukkan kecepatan 
aliran fluida dengan permeabilitas batuan, viskositas fluida serta gradien tekanan antar jarak tempuh aliran. Berikut merupakan persamaan Darcy:

$$
\bar{u}=-\frac{\kappa}{\mu}(\nabla p+\rho g \nabla \mathrm{D})
$$

Dengan $\mathbf{u}, \mu, \kappa, \mathrm{p}, \rho$, dan D berturut turut adalah kecepatan aliran fluida, viskositas dinamik fluida, permeabilitas batuan, tekanan, densitas, dan ketinggian yang bergantung pada garavitasi. Dengan mengabaikan efek dari percepatan gravitasi, dan mengasumsikan fluida tak termampatkan, maka persamaan kontinuitas dapat dituliskan sebagai berikut:

$\nabla \cdot \vec{u}=0$

Dengan mensubstitusikan persamaan (2) ke persamaan (3), maka didapatkan:

$$
\nabla \cdot\left(\frac{\kappa}{\mu} \nabla p\right)=0
$$

Jika permeabilitas dan viskositas konstan maka persamaan (4), menjadi:

$$
\nabla^{2} p=0
$$

\subsubsection{Persamaan Konduksi dan Konveksi}

Untuk mengetahui distribusi temepartur pada sistem panas bumi digunakan persamaan perpindahan panas konduksi-konveksi. Berikut adalah persamaannya

$\nabla .(k \nabla T)-\rho C_{p} \vec{u} . \nabla T=Q_{G}$

Pada kasus sistem panas bumi $\mathrm{Q}_{\mathrm{G}}$ menggambarkan sumber panas bumi. Dalam tulisan ini $\mathrm{Q}_{\mathrm{G}}$ diasumsikan sama dengan nol. Sedangkan $\mathrm{k}$ adalah konduktivitas panas yang menggambarkan seberapa mudah panas dapat ditransmisikan. Kemudian $\rho$ densitas fluida dan $\mathrm{C}_{\mathrm{p}}$ adalah kapasitas panas.

\section{HASIL DAN PEMBAHASAN}

\subsection{Hasil Pemodelan Aliran Fluida pada Reservoir Panas Bumi}

Kecepatan aliran fluida ditentukan dengan menggunakan persamaan (2). Hasilnya berupa nilai kecepatan. Dalam hal ini diandaikan pada model reservoir non topografi aliran fluida yang masuk pada sisi batas kiri sebesar $10^{-4} \mathrm{~m} / \mathrm{s}$ dan aliran fluida yang keluar sebesar $-10^{-4}$. Pada model ini dibuat model homogen, dua lapis, dan 3 lapis. Dimana lapisan bawah diberi nilai permeabilitas lebih besar dari pada lapisan atas. Pada reservoir topografi lembah aliran yang masuk pada batas sisi atas dan keluar pada batas sisi bawah. Pada topografi gunung aliran fluida yang masuk pada batas sisi kiri dan keluar pada sisi kanan dengan nilai $\mathrm{q}_{\text {in }}$ dan $\mathrm{q}_{\text {out }}$ sama dengan model reservoir non topografi dan topografi lembah. Berikut hasil pemodelannya: 


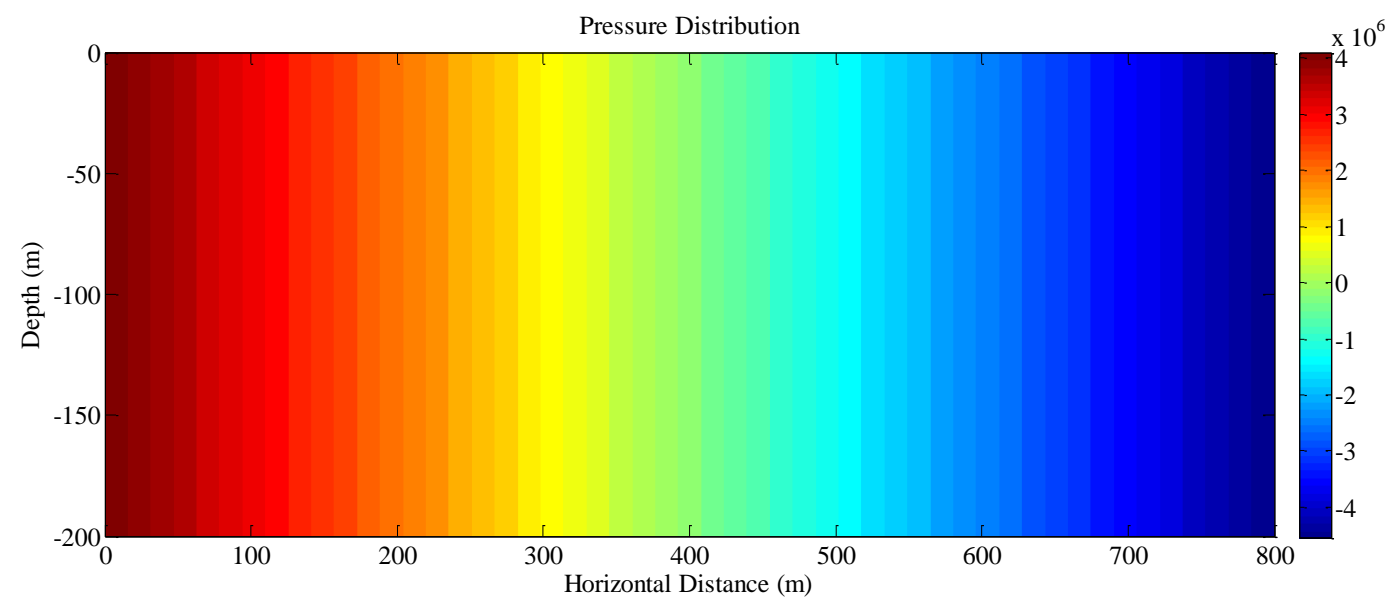

Gambar 5 Distribusi tekanan pada reservoir homogen.

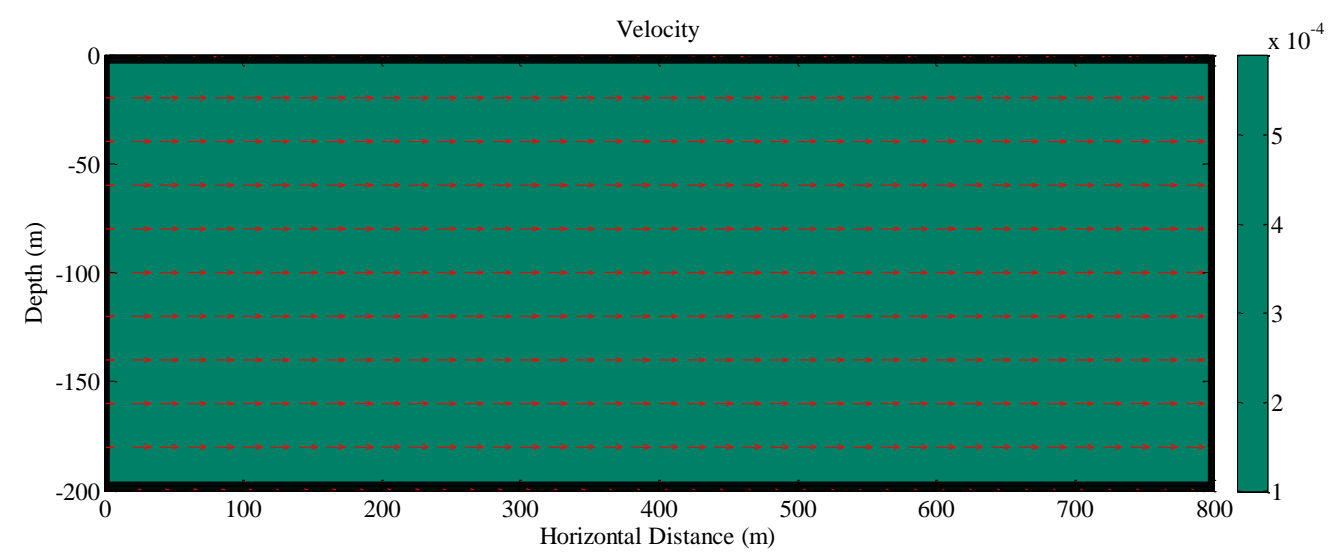

Gambar 6 Arah aliran fluida pada reservoir homogen

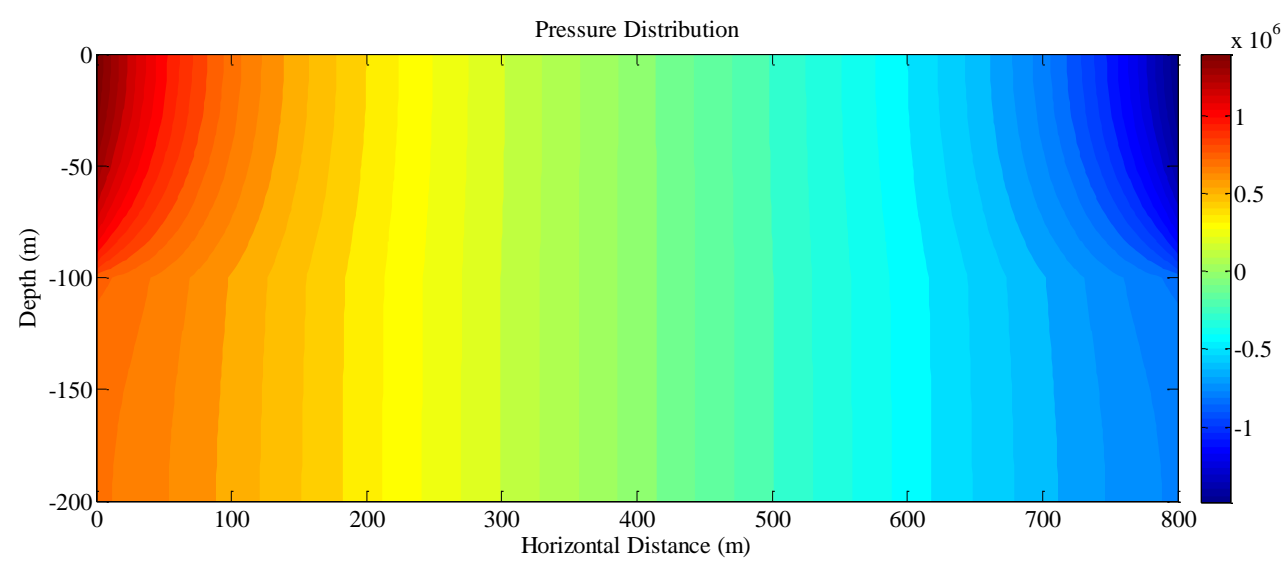

Gambar 7 Distribusi tekanan pada reservoir 2 lapis 


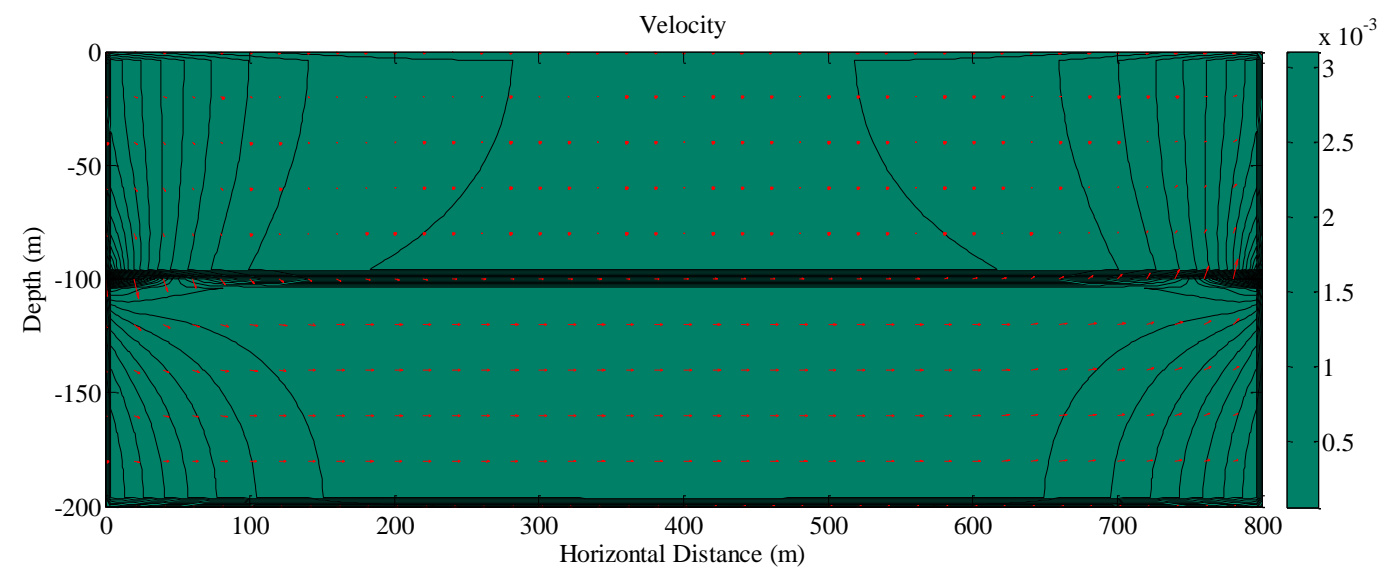

Gambar 8 Arah aliran fluida pada resesvoir 2 lapis

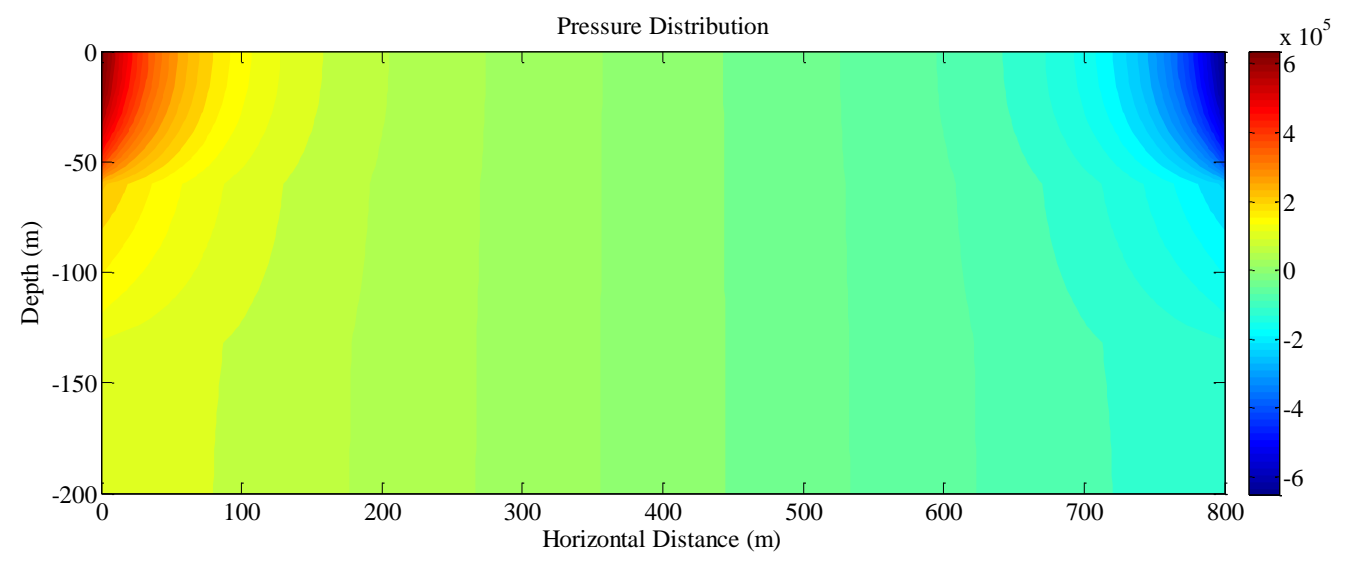

Gambar 9 Distribusi tekanan pada reservoir 3 lapis

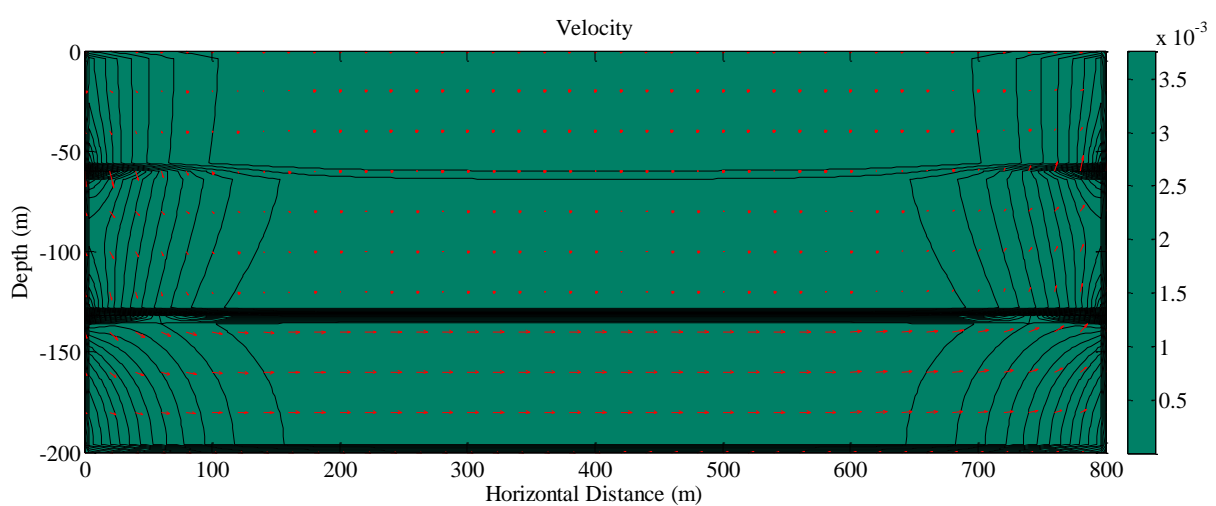

Gambar 10 Arah aliran fluida pada reservoir 3 lapis

Dari gambar diatas dapat dilihat bahwa semakin besar nilai permeabilitas yang diberi, maka nilai tekanan akan semakin kecil dan dapat juga dilihat bahwa semakin besar nilai permeabilitas yang diberi maka kecepatan aliran fluida akan semakin cepat. 


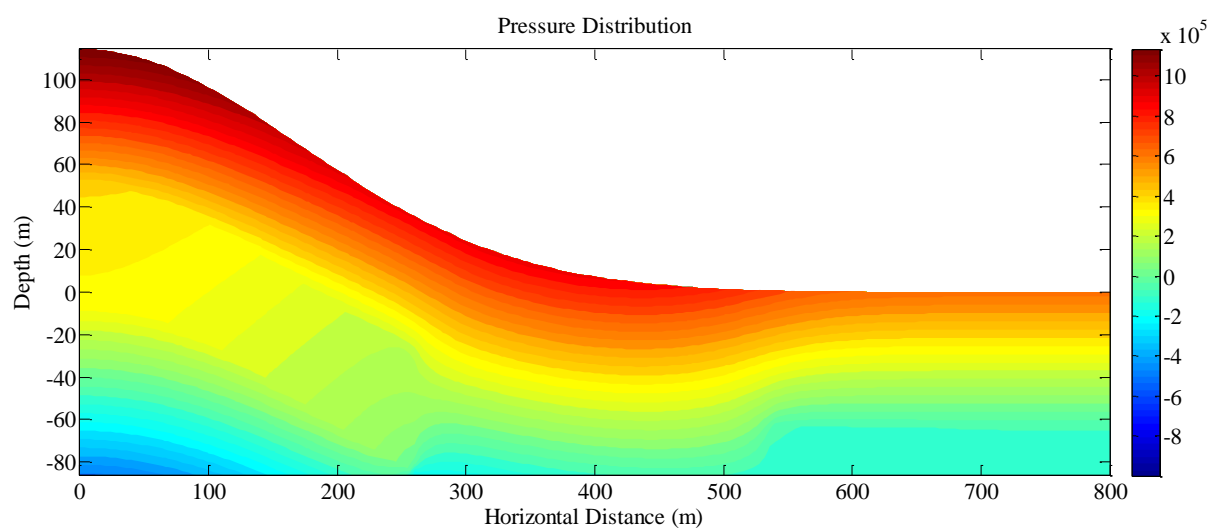

Gambar 11 Distribusi tekanan pada reservoir topografi lembah

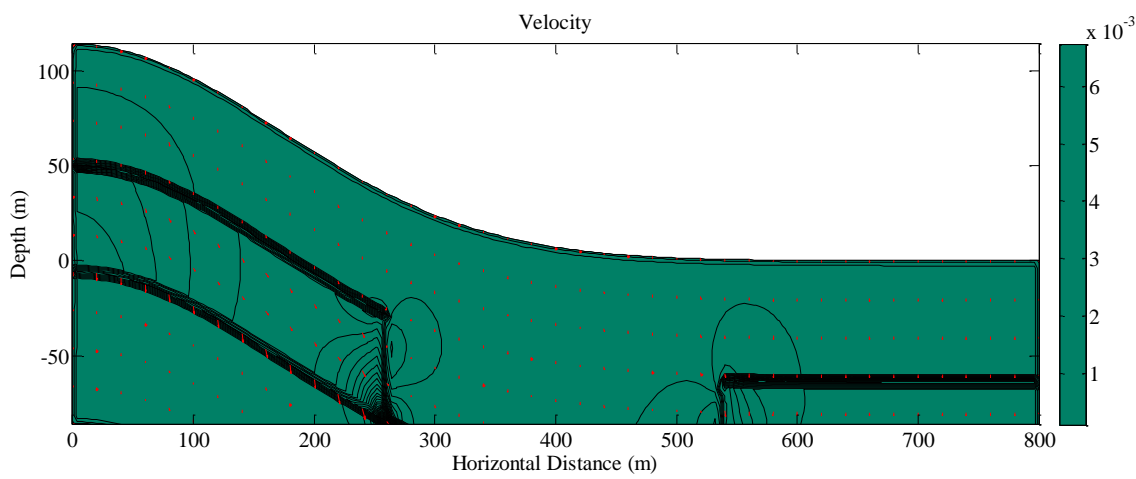

Gambar 12 Arah aliran fluida pada reservoir topografi lembah

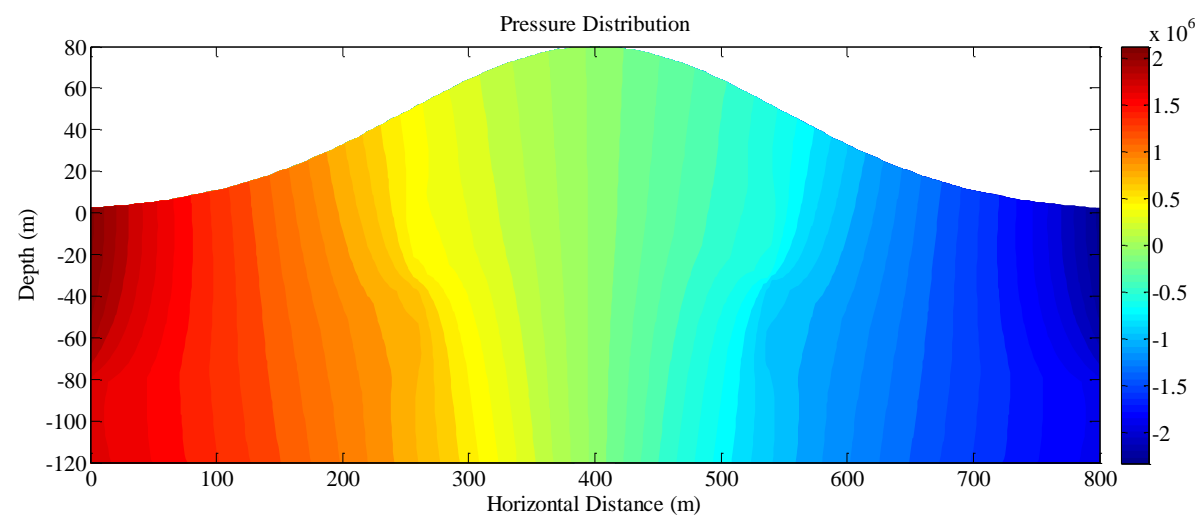

Gambar 13 Distribusi tekanan pada reservoir topografi gunung 


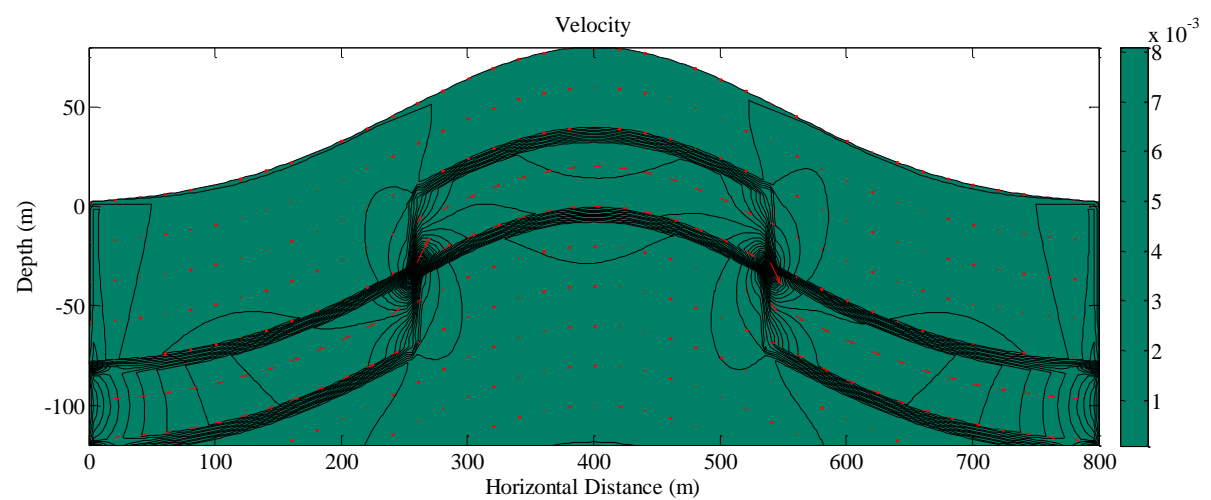

Gambar 14 Arah aliran fluida pada reservoir topografi gunung

Pada reservoir topografi lembah dan gunung distribusinya mengikuti model topografinya dan aliran fluidanya semakin cepat pada daerah yang permeabilitasnya besar.

\subsection{Hasil Pemodelan Perpindahan Panas Konduksi-Konveksi}

Distribusi temperatur ditentukan dengan menggunakan persamaan (6). Dalam hal ini diasumsikan batas sisi bawah sebagai bagian dasar reservoir berupa batuan panas dengan temperatur sebesar $500{ }^{\circ} \mathrm{C}$ yang mentransfer panasnya secara konduksi dan konveksi ke dalam reservoar yang berisi fluida air, batas sisi atas diasumsikan sebagai temperatur awal reservoir dengan temperatur $100{ }^{\circ} \mathrm{C}$, sedangkan pada batas sisi kiri dan kanan diasumsikan tidak ada panas yang keluar pada reservoir. Berikut hasil pemodelannya:

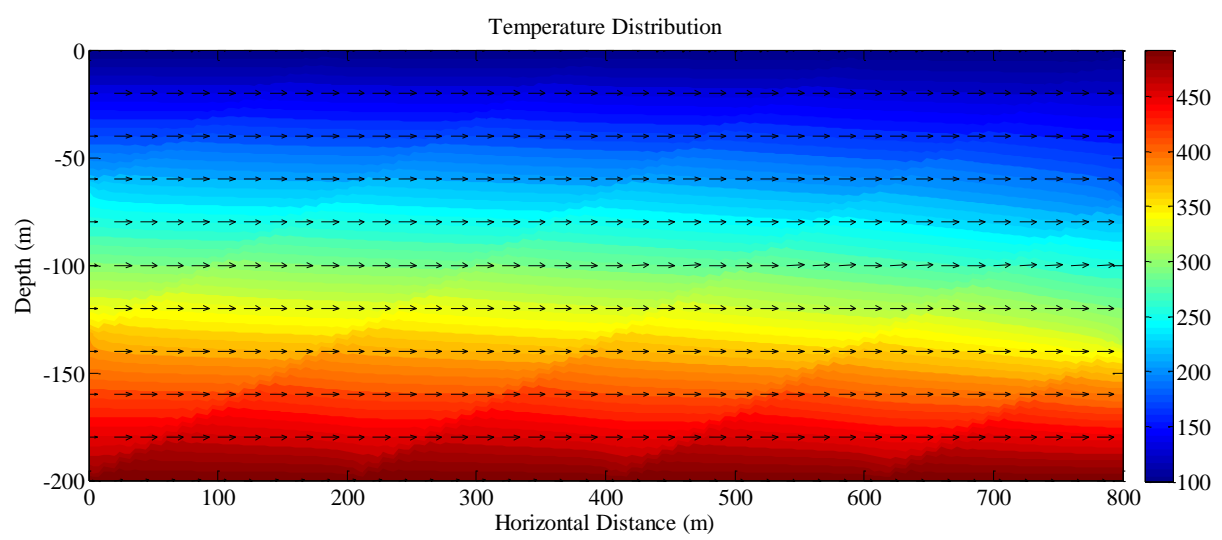

Gambar 15 Distribusi temperatur pada reservoir homogen

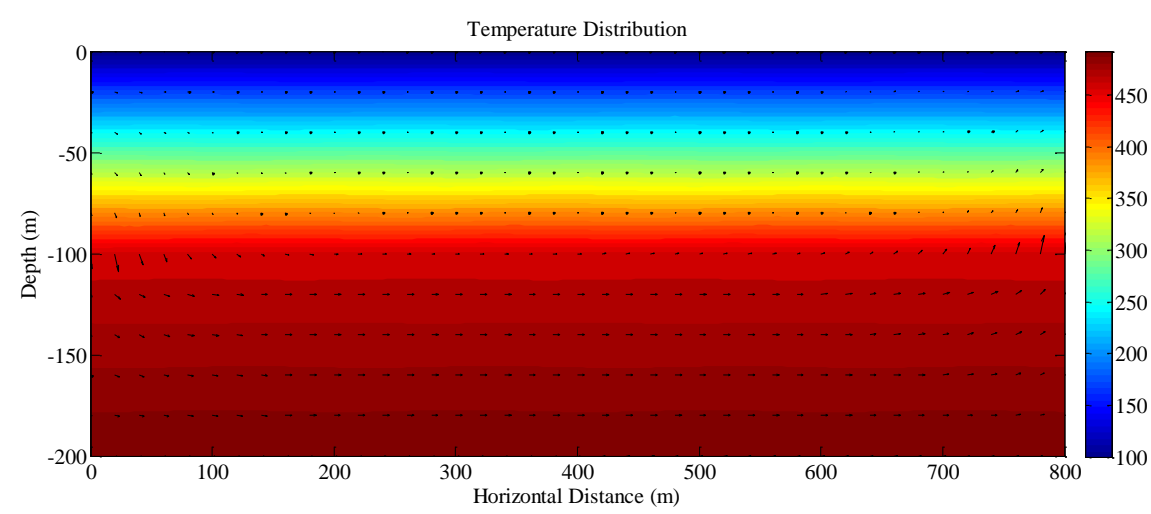


Gambar 16 Distribusi temperatur pada reservoir 2 lapis

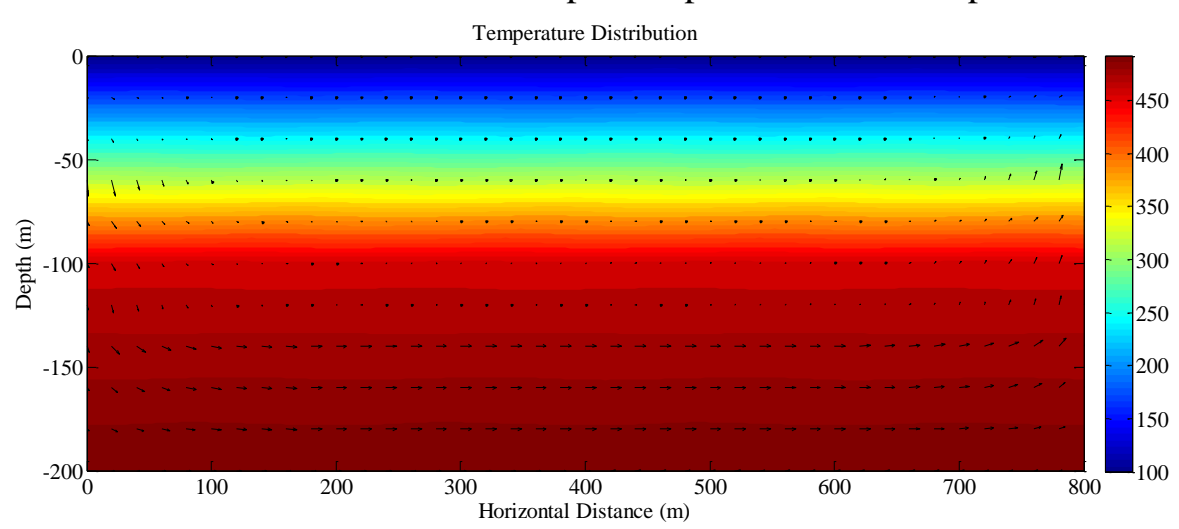

Gambar 17 Distribusi temperatur pada reservoir 3 lapis

Pada pemodelan perpindahan panas konduksi-konveksi pada gambar diatas dapat disimpulkan bahwa pada lapisan yang nilai konduktivitas besar, perubahan temperaturnya lebih kecil dibandingkan dengan lapisan yang nilai konduktivitas yang kecil.

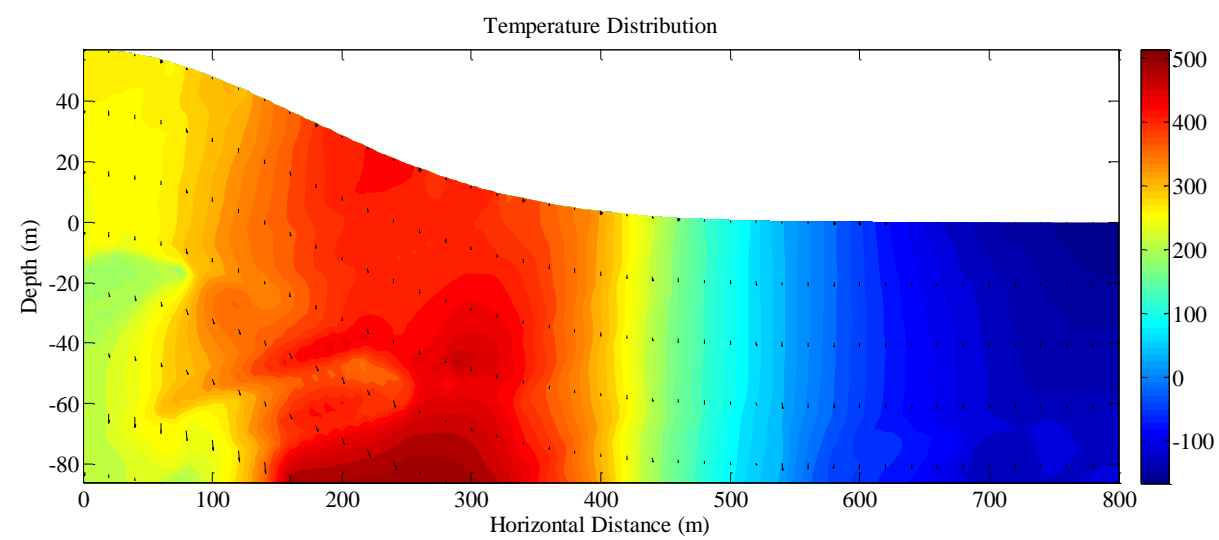

Gambar 18 Distribusi temperatur pada topografi lembah

Pada model diatas terjadi perpindahan panas secara konduksi yaitu antara sumber panas dan lingkungan sekitarnya, sedangkan antara sumber panas dan fluida terjadi perpindahan panas secara konveksi.

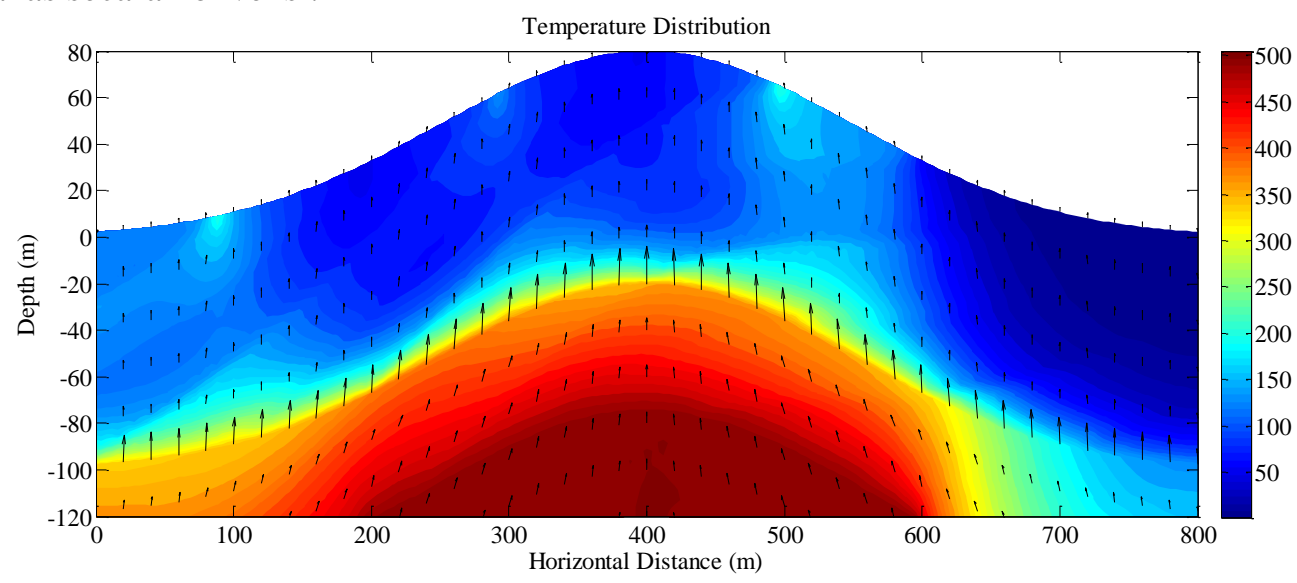

Gambar 19 Distribusi temperatur pada topografi gunung 
Pada model diatas terjadi perpindahan panas secara konduksi yaitu antara sumber panas dan lingkungan sekitarnya. Aliran konveksi tidak begitu terbentuk. Ini diakibatkan karena penempatan nilai permeabilitas suatu batuan pada model tidak diatur sedemikian rupa sehingga tidak terbentuk seperti yang real.

\section{KESIMPULAN}

Dari hasil pemodelan kecepatan aliran fluida dan perpindahan panas konduksikonveksi disimpulkan bahwa nilai tekanan bergantung pada nilai permeabilitas batuan. Semakin kecil nilai permeabiltas maka nilai tekanan semakin besar dan aliran fluida juga ditentukan pada nilai permeabilitas. Semakin besar nilai permeabilitas maka kecepatan aliran fluida akan semakin cepat. Distribusi temperatur bergantung pada nilai konduktivitas batuan. Semakin besar nilai konduktivitas maka distribusi temperatur akan semakin kecil.

\section{DAFTAR PUSTAKA}

Anonim.2007.http://infoenergi.wordpress.com/2007/03/13egs-dan-masa-depan-energipanasbumi-di-indonesial

C. Polycarpu. Anastasis. 2006. An Introduction to the Finite Element Method in Electromagnetism. Morgan \& Claypool Publisher : USA.

Gold, T.L.:" Verttical Two-Phasa Steap-Water flow in Geothermal Well”, J. Pet. Tech. (Aug.1974) 833-842.

Kumar C P 2009 Groundwater Flow Models. Scientist Institute of hydrology, Rookie Uttaranchal.

Lewis, R. W., K. Morgan, H.R. Thomas, and K.N. seetharamu, 1996, The Finite Element Method in Heat Transfer Analysis, John Wiley and sons, Chichester, West Sussex, England

Lewis, R. W., P. Nithiarasu, and K. N. Seetharamu, 2004, Fundamental of the Finite Element Method for Heat and fluid flow, John Wiley and sons, Chichester, West Sussex, England.

R. Baigoria, L.O. Ottone, J.L. Pousa, F. Di Leo, J. Maranon, AOSTRA J.R., 8(1992)1-10.

R, Salvius. 2014. Mathematical Modelling of Groundwater Flow. University of Dar es Saalam.

Singarimbun, A. A Numerical Model of Magmatic Hydrothermal System A Case Srudy of Kuju Volcano, Central Kyushu, Japan-Kyushu University, Fukuoka Japan. 1997 